Article

\title{
Local and Average Structural Changes in Zeolite A upon Ion Exchange
}

\author{
Lisa Price ${ }^{1}$, Ka Ming Leung ${ }^{2}$ and Asel Sartbaeva ${ }^{1, *}$ (1) \\ 1 Department of Chemistry, University of Bath, Bath BA2 7AY, UK; lisa.a.price@btinternet.com \\ 2 Inorganic Chemistry Lab, South Parks Road, University of Oxford, Oxford OX1 3QR, UK; \\ ka.leung.thomas@gmail.com \\ * Correspondence: a.sartbaeva@bath.ac.uk; Tel.: +44-(0)-1225-38-5410
}

Received: 21 August 2017; Accepted: 7 December 2017; Published: 12 December 2017

\begin{abstract}
The infamous 'structure-property relationship' is a long-standing problem for the design, study and development of novel functional materials. Most conventional characterization methods, including diffraction and crystallography, give us a good description of long-range order within crystalline materials. In recent decades, methods such as Solid State NMR (SS NMR) are more widely used for characterization of crystalline solids, in order to reveal local structure, which could be different from long-range order and sometimes hidden from long-range order probes. In particular for zeolites, this opens a great avenue for characterization through studies of the local environments around $\mathrm{Si}$ and $\mathrm{Al}$ units within their crystalline frameworks. In this paper, we show that some structural modifications occur after partially exchanging the extraframework $\mathrm{Na}^{+}$ions with monovalent, $\mathrm{Li}^{+}, \mathrm{K}^{+}, \mathrm{Rb}^{+}$and $\mathrm{NH}_{4}{ }^{+}$and divalent, $\mathrm{Ca}^{2+}$ cations. Solid state NMR is deployed to study the local structure of exchanged materials, while average stricture changes can be observed by powder diffraction (PXRD). To corroborate our findings, we also employ Fourier Transform Infrared spectroscopy (FT-IR), and further characterization of some samples was done using Scanning Electron Microscopy (SEM) and Energy-Dispersive X-ray spectroscopy (EDX).
\end{abstract}

Keywords: zeolite; solid state NMR; ion exchange; synthesis; characterization

\section{Introduction}

Zeolites are aluminosilicate porous minerals. Many zeolites occur in nature as aluminosilicate minerals. To date, we can make more than 200 synthetic zeolites in the laboratory [1,2]. They are classed as porous materials as they possess cages, channels and open void spaces within their highly crystalline frameworks. Each zeolite framework has a unique structure, and because there is such a variety of zeolite structures, there is also a very wide diversity of zeolite applications. Synthetic zeolites are used as green, re-usable catalysts in industrial processes as heterogeneous catalysts for processes that involve hydro-cracking, acrylation, oxidation and reforming. Most zeolite syntheses employ Organic Structure Directing Agents (OSDAs), such as TMA-OH (Tetramethylammonium Hydroxide) or crown-ether, which act as templates to guide the formation of particular types of zeolite pores and channels [3-6]. This reduces the chance of producing competing zeolite phases. However, due to the high manufacturing costs of producing these organic materials, which cannot be recovered after calcination, current research is becoming more concerned with optimising synthesis conditions in order to produce pure zeolites in the absence of OSDAs [3,7]. Here, we performed a low temperature synthesis of small zeolite A (Na-A) crystals without the use of OSDAs, and the corresponding LTA framework (Linde Type A) is shown in Figure 1. 


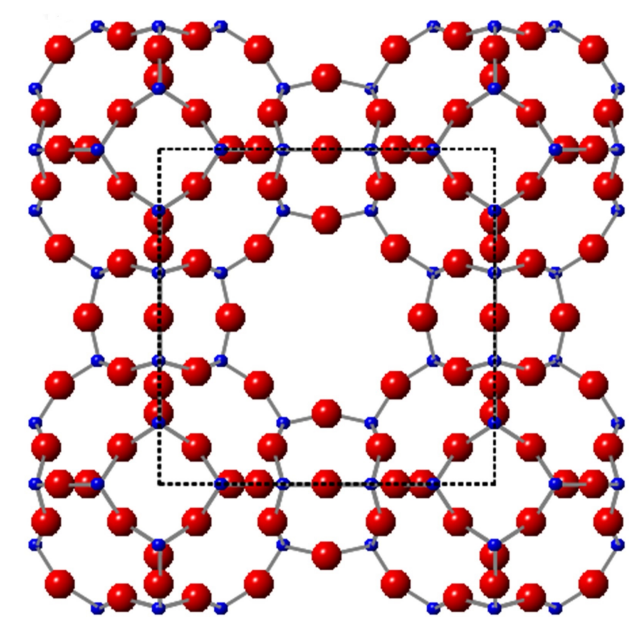

Figure 1. Linde Type A (LTA) framework with the $\alpha$ cage as the unit cell in the middle (black square). Red spheres: oxygens; blue: $\mathrm{Si} / \mathrm{Al}$ atoms.

$\mathrm{Na}-\mathrm{A}$ is a commercially important zeolite used in industry for catalysis, adsorption and industrial gas separations [8]. More recently, its sustainability as a drug delivery system has been investigated [9]. One of its greatest applications, however, is ion exchange; in particular, rapid $\mathrm{Na}^{+} / \mathrm{Ca}^{2+}$ exchange. Consequently, Na-A is very effective in water softening, and one of its main functions is in washing powders as a detergent builder [10].

Ion exchange can also produce zeolites with different properties. For example, K-A is commonly used in the ethanol drying processes [11] and partially-exchanged $\mathrm{K} / \mathrm{Na}-\mathrm{A}$ is used to separate $\mathrm{CO}_{2}$ from $\mathrm{CO}_{2} / \mathrm{N}_{2}$ dry mixtures [12]. Ca-A zeolites are important in industry, where they selectively adsorb linear alkanes from a mixture of branched alkanes [13], and $\mathrm{Na}^{+} / \mathrm{NH}_{4}{ }^{+}$exchange is useful in minimising environmental pollution and eutrophication [14-17]. Li-A was proposed as a possible delivery material for pharmacological studies [18]. Li-exchanged zeolites are also used for the separation of nitrogen from air [19]. In this work, we carried out aqueous ion exchange of monovalent alkali metals: $\mathrm{Li}^{+}$, $\mathrm{K}^{+}, \mathrm{Rb}^{+}$and $\mathrm{NH}_{4}{ }^{+}$and divalent $\mathrm{Ca}^{2+}$ into zeolite $\mathrm{A}$ crystals produced from a low temperature and organic template-free synthesis and performed analysis using solid state NMR and other methods to determine the structural effects of the exchange. Previously, solid state NMR has been used to study other zeolites [20-28].

\section{Results and Discussion}

\subsection{Na-A, Li-A, K-A and Rb-A}

The powder patterns of the hydrated Na-A samples are consistent with those recorded in the literature for pure phase zeolite A crystals [29,30]. Figure 2 shows the indexed pattern for Na-A, synthesised at $40{ }^{\circ} \mathrm{C}$ for $24 \mathrm{~h}$. Reflection peaks corresponding to both Na-A and Faujasite (FAU) phases [30] were observed when the zeolites were synthesised at $50^{\circ} \mathrm{C}$ for $24 \mathrm{~h}$ and at $40{ }^{\circ} \mathrm{C}$ for $48 \mathrm{~h}$, as shown in Figure 3. It is evident that, if given enough time or if heated above a certain temperature, there is a tendency for the metastable LTA framework structure to subsequently transform into the FAU framework $[7,31]$. Careful control of the synthesis conditions is, therefore, necessary to avoid the formation of the unwanted polymorph, which is a ubiquitous problem in synthesising zeolites in the absence of OSDAs. The low temperature of $40^{\circ} \mathrm{C}$ limits the presence of these competing phases. 


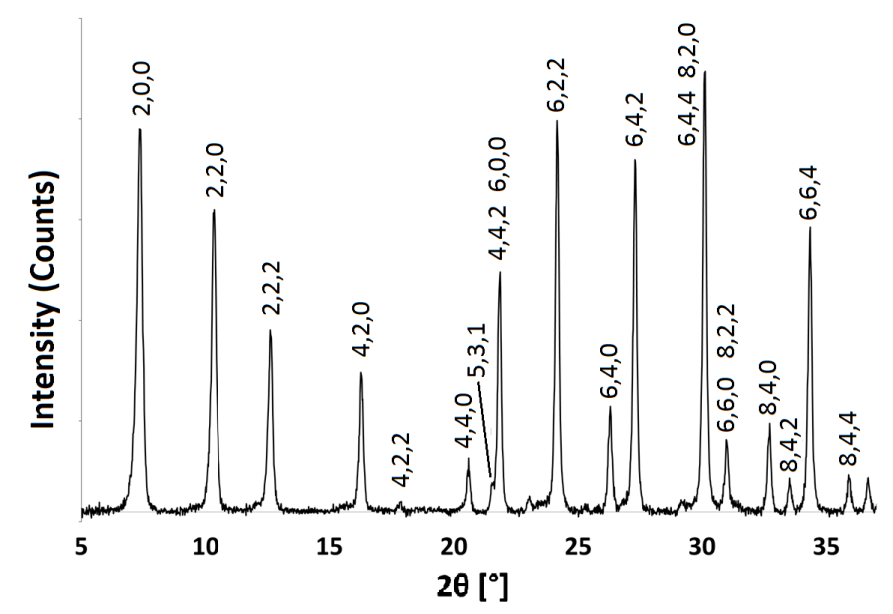

Figure 2. PXRD pattern for Na-A synthesised at $40{ }^{\circ} \mathrm{C}$ for $24 \mathrm{~h}$, indexed as the LTA framework.

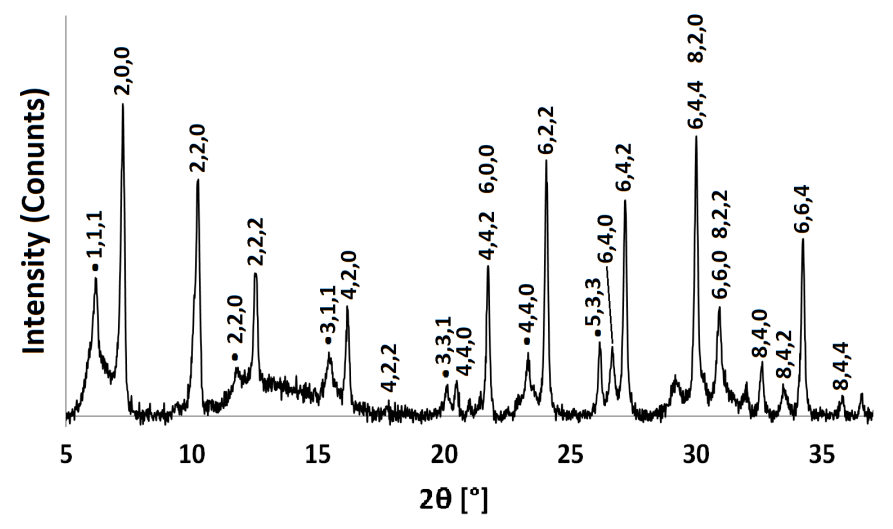

Figure 3. PXRD pattern for Na-A synthesised at $40{ }^{\circ} \mathrm{C}$ for $48 \mathrm{~h}$. Characteristic Faujasite (FAU) framework peaks are indexed with black dots.

In this investigation, we decided to study all samples after one ion exchange only. The extent of exchange was quantified from the filtrates using a sodium ion selective electrode (ISE). For each sample, even after one exchange, we see good, although not complete, ion exchange. This is not surprising as sometimes as many as 8-10 steps are required for a complete exchange to occur [32]. Results show that the extent of exchange decreases with increasing cation size, $\mathrm{Li}^{+}>\mathrm{K}^{+}>\mathrm{Rb}^{+}$. The steric restrictions of the zeolite pores make full exchange difficult to obtain, particularly for those ions with large ionic radii. Energy Dispersive X-ray (EDX) elemental analysis was also carried out. In all samples, it was evident that partial exchange had taken place, as residual $\mathrm{Na}^{+}$ions were detected.

PXRD and FT-IR analyses show that there is no significant alteration to either the long-range crystal order or the local framework structure of Na-A after exchange with $\mathrm{Li}^{+}, \mathrm{K}^{+}$and $\mathrm{Rb}^{+}$ions. These monovalent alkali cations vary in their ionic radii, and changes in the PXRD peak intensities are expected to occur as a result of these cations occupying slightly different sites in the pores. Figure 4 shows the PXRD patterns for the alkali metal exchanged zeolites. For K-A, the $(4,4,0)$ reflection almost disappears, whereas the $(4,2,2)$ and $(8,0,0)$ peaks increase in intensity. These results are in agreement with those observed by Lührs et al., where complete exchange with $\mathrm{K}$ and $\mathrm{Ca}$ was studied using diffraction and structure refinement [33]. The PXRD pattern for Rb-A is also slightly different. The characteristic intensities of the first four Na-A reflections are altered; most noticeable is the increase in the intensity of the $(2,2,0)$ reflection. 


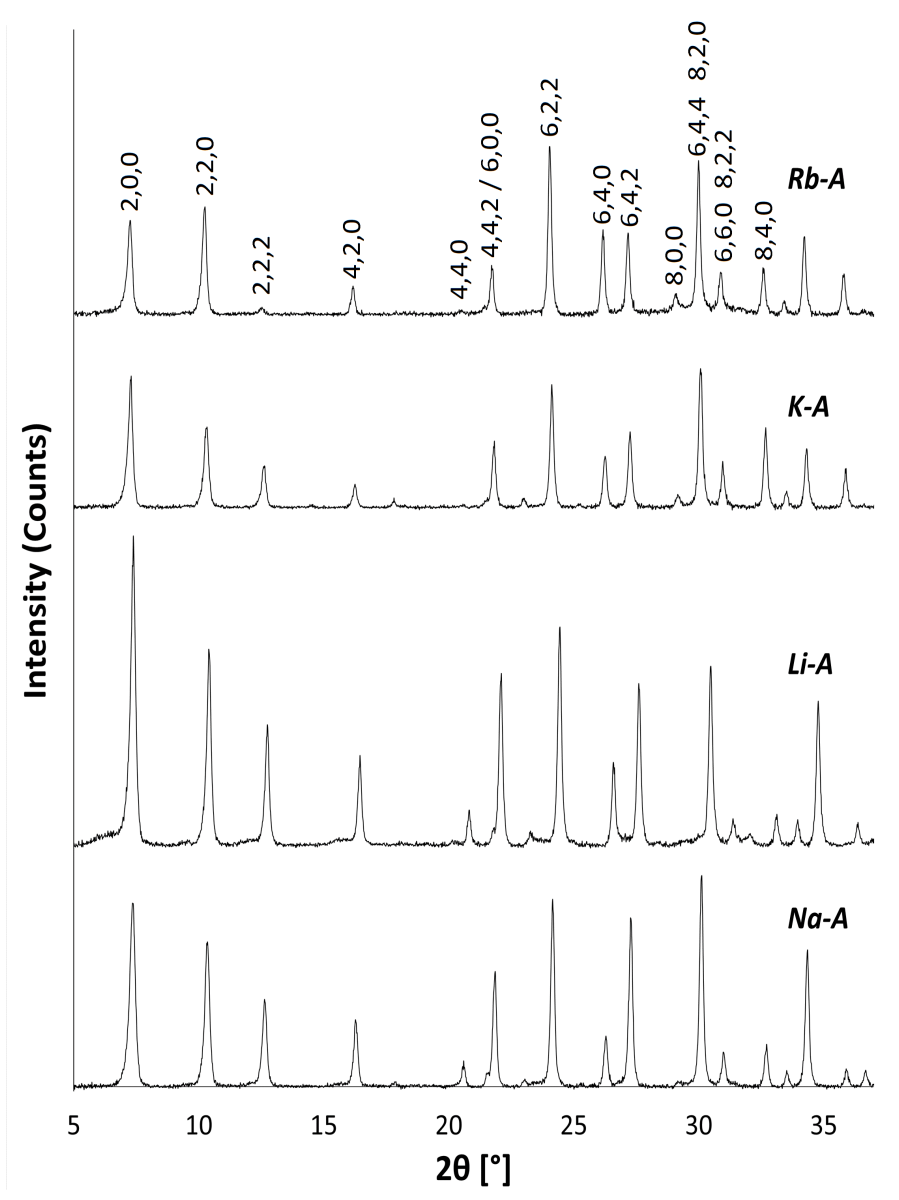

Figure 4. PXRD patterns for Na-A, Li-A, K-A and Rb-A.

The unit cell parameters $(a)$ for the exchanged zeolites were calculated from the PXRD peak positions and Miller indices using the program UnitCell [34] and are shown in Table 1. All samples have cubic symmetry, and it can be seen that the unit cell size decreases by about $1 \%$ on exchanging larger $\mathrm{Na}^{+}(1.02 \AA)$ for smaller $\mathrm{Li}^{+}(0.59 \AA)$ ions and increases slightly on exchange with larger $\mathrm{K}^{+}(1.38 \AA)$ and $\mathrm{Rb}^{+}(1.49 \AA)$ ions [35]. Correspondingly, an increase in the lattice parameter is progressive from $\mathrm{Li}<\mathrm{Na}<\mathrm{K}<\mathrm{Rb}-\mathrm{A}$, in accordance with the increasing ionic radii of the monovalent cations.

Table 1. Unit cell parameters for the exchanged zeolites.

\begin{tabular}{lcccc}
\hline & Li-A & Na-A & K-A & Rb-A \\
\hline Unit cell parameter, $a(\AA)$ & $24.151(2)$ & $24.435(2)$ & $24.454(2)$ & $24.486(3)$ \\
\hline
\end{tabular}

The FT-IR spectra for Li-A, Na-A, K-A and Rb-A all display the fundamental zeolite framework vibration $v_{\max } / \mathrm{cm}^{-1}$ at $959,968,972$ and 969 , respectively, corresponding to the asymmetric $v_{(O-T-O)}$ stretch, shown in Figure 5. In addition, the framework symmetric $v_{(O-T-O)}$ stretch occurs at $v / \mathrm{cm}^{-1}$ 684, 664, 663 and 666 for Li-A, Na-A, K-A and Rb-A, respectively. The broad peaks at $3350-3450 \mathrm{~cm}^{-1}$ and the weaker peaks at $1650 \mathrm{~cm}^{-1}$ observed in all spectra correspond to the $v_{(O-H)}$ stretching and $\delta_{(H-O-H)}$ bending vibrations of water molecules in the hydrated samples. The only noticeable differences in the spectra are that the framework $v_{(O-T-O)}$ asymmetric stretch shifts to slightly a higher wavenumber and the $v_{(O-T-O)}$ symmetric stretch shifts to slightly a lower wavenumber, with increasing cation size, $\mathrm{Li}^{+}<\mathrm{Na}^{+}<\mathrm{K}^{+}$. 


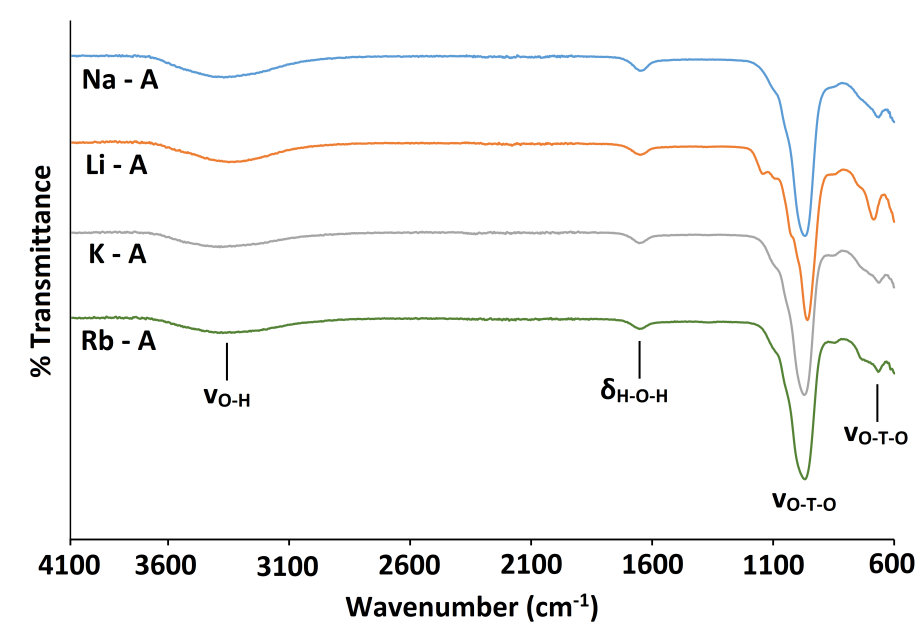

Figure 5. FT-IR spectra for Na-A (blue line) and cation-exchanged Li-A (orange line); K-A (grey line) and $\mathrm{Rb}-\mathrm{A}$ (green line).

For the parent Na-A zeolites, ${ }^{29} \mathrm{Si}$ and ${ }^{27} \mathrm{Al}$ MASNMR spectra contain one peak at $\delta-89.54 \mathrm{ppm}$ and $\delta 58.41 \mathrm{ppm}$, respectively, confirming that the $\mathrm{Si} / \mathrm{Al}$ ratio of the framework is one. This is in agreement with data reported by Thomas et al. [24] for a single silicon, $\mathrm{Si}(\mathrm{OAl})_{4}$, and aluminium environment, $\mathrm{Al}(\mathrm{OSi})_{4}$, in Linde Type A zeolites. ${ }^{27} \mathrm{Al}$ MAS NMR spectra for the exchanged zeolites also display one sharp peak between $\delta 57 \mathrm{ppm}$ and $60 \mathrm{ppm}$, pertaining to $\mathrm{Al}(4 \mathrm{Si})$ units. Likewise, ${ }^{29} \mathrm{Si}$ spectra for Li-A, K-A and Rb-A are also dominated by a single sharp peak at $\delta-87.23 \mathrm{ppm}$, $-89.83 \mathrm{ppm}$ and $-89.87 \mathrm{ppm}$, respectively. These peaks all lie within the chemical shift range for which $\mathrm{Si}(4 \mathrm{Al})$ units can occur $(\delta-80.0 \mathrm{ppm}--90.5 \mathrm{ppm}$ from TMS) [28]. Some small, low intensity peaks at $\delta-84.02 \mathrm{ppm},-87.96 \mathrm{ppm}$ and $-85.03 \mathrm{ppm}$ are observed in the $\mathrm{Li}, \mathrm{K}$ and $\mathrm{Rb}-\mathrm{A}$ samples, respectively. These are identified as silanol peaks. From deconvolution of the $\mathrm{Li}, \mathrm{K}$ and $\mathrm{Rb}-\mathrm{A}{ }^{29} \mathrm{Si} \mathrm{NMR}$ spectra as shown in Figure 6, the $\mathrm{Si} / \mathrm{Al}$ ratios were calculated to be one using Equation (1) $[22,28]$ :

$$
\frac{S i}{A l}=\frac{\sum_{n=0}^{n=4} I_{S i(n A l)}}{\sum_{n=0}^{n=4}\left(\frac{n}{4}\right) I_{S i(n A l)}}
$$

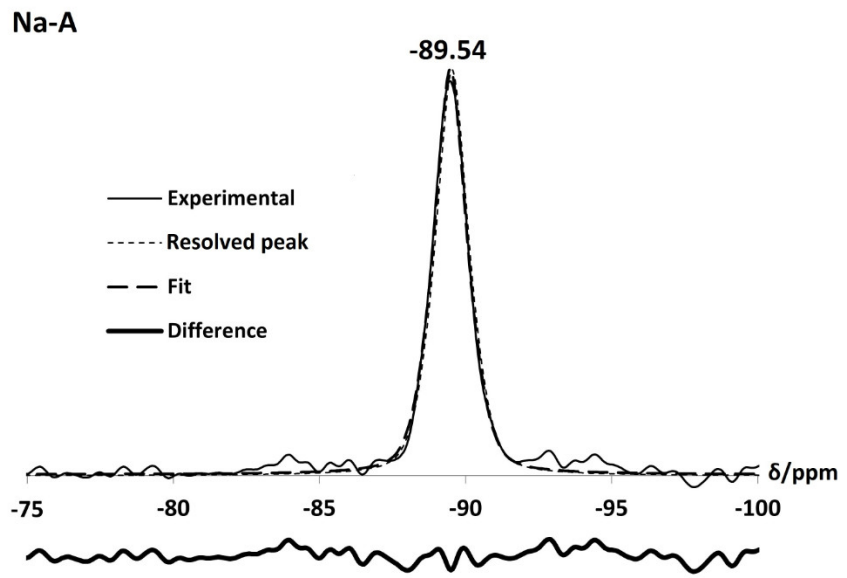

Figure 6. Cont. 

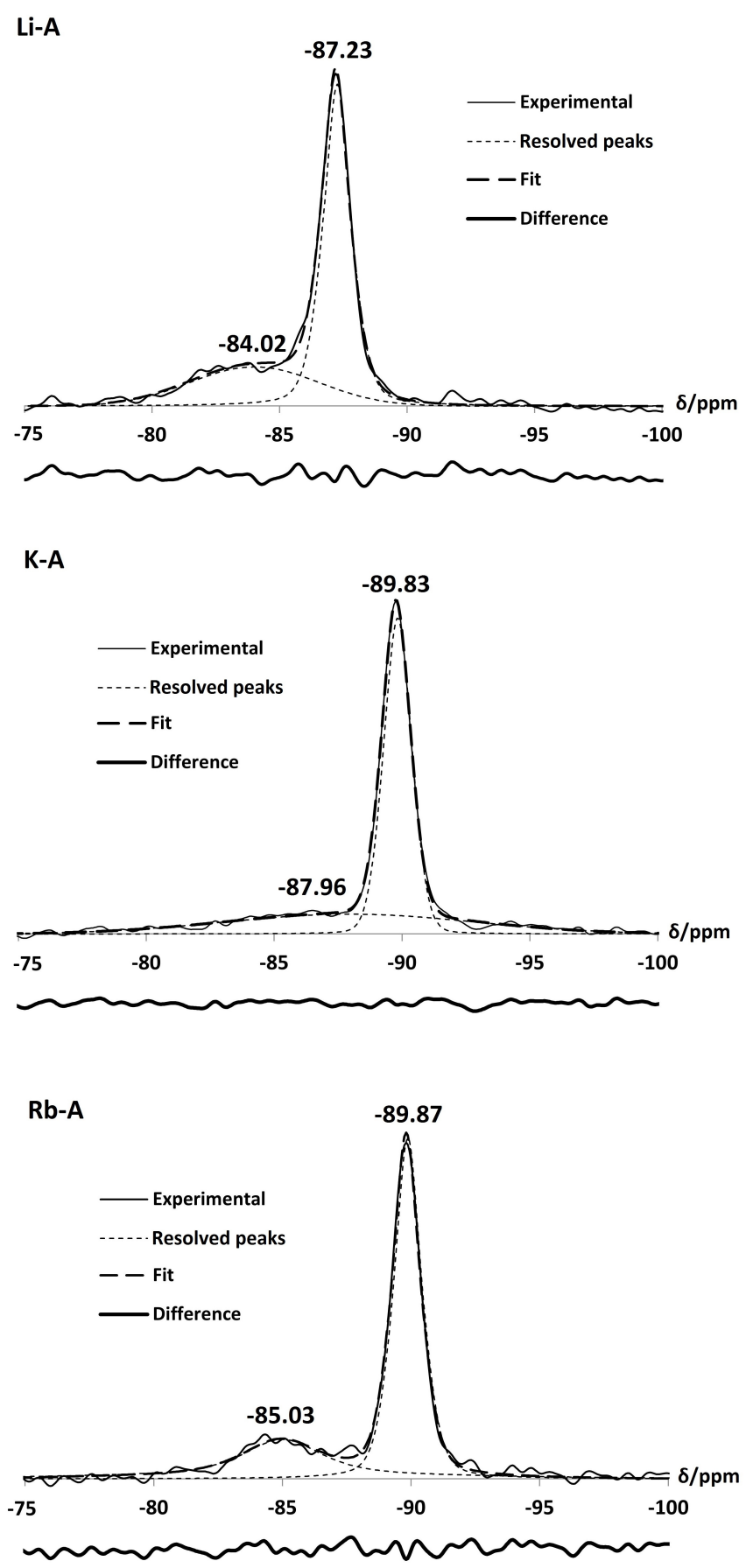

Figure 6. ${ }^{29} \mathrm{Si}$ NMR spectrum of the as-synthesised Na-A and monovalent cation-exchanged Li-A, K-A and $\mathrm{Rb}-\mathrm{A}$.

It is also interesting to note that the $\mathrm{Si}(4 \mathrm{Al})$ peak for Li-A is significantly shifted to a lower field, centred at $\delta-87.23 \mathrm{ppm}$, in comparison to that of the parent Na-A peak, at $\delta-89.54 \mathrm{ppm}$. The linear relationship between the average Si-O-T framework bond angles, $(\alpha)$ and ${ }^{29} \mathrm{Si}$ chemical shifts can offer an explanation for this difference. Table 2 shows the $\mathrm{Si} / \mathrm{Al}$ ratios and average T-O-T bond angles that were calculated from the deconvoluted ${ }^{29} \mathrm{Si}$ NMR spectra using Equation (2) [36].

$$
\delta={ }^{29} \operatorname{Si}(\mathrm{ppm})=-5.230-0.570 \alpha
$$


Table 2. ${ }^{29} \mathrm{Si} \mathrm{NMR}$ data: $\mathrm{Si} / \mathrm{Al}$ ratios and average T-O-T bond angles for $\mathrm{Li}, \mathrm{Na}, \mathrm{K}$ and $\mathrm{Rb}-\mathrm{A}$. The angular values are estimated based on NMR data using the regression relationship from [36], and we estimate the accuracy on angles up to \pm 2 degrees.

\begin{tabular}{ccccc}
\hline & Li-A & Na-A & K-A & Rb-A \\
\hline $\mathrm{Si} / \mathrm{Al}$ & 1 & 1 & 1 & 1 \\
$\angle \mathrm{T}-\mathrm{O}-\mathrm{T}\left[\alpha\left(^{\circ}\right)\right]$ & 143.9 & 147.9 & 148.6 & 148.4 \\
\hline
\end{tabular}

Na-A zeolites, synthesised at $40{ }^{\circ} \mathrm{C}$ for $24 \mathrm{~h}$, are shown to have good cation exchange ability with $\mathrm{Li}^{+}, \mathrm{K}^{+}$and $\mathrm{Rb}^{+}$ions. The only noticeable differences between these exchanged zeolites are the sizes of the unit cells and average framework T-O-T bond angles, which increase accordingly with increasing cation size $\mathrm{Li}<\mathrm{Na}<\mathrm{K}<\mathrm{Rb}$.

\section{2. $\mathrm{NH}_{4}-\mathrm{A}$}

Exchange with $\mathrm{NH}_{4}{ }^{+}$ions compromises some of the long-range order of the zeolite A crystals, inferred by the broad PXRD peaks and low signal to noise ratio, as seen in Figure 7. NMR and FT-IR spectra also indicate that the local framework environment is affected. Figure 8 shows a weak peak at $v_{(\mathrm{NH})} / \mathrm{cm}^{-1} 1453$ in the FT-IR spectrum, which confirms that exchange has taken place. The asymmetric $v_{(O-T-O)}$ stretch is, however, weaker and broader than that of the parent spectrum and is shifted toward a higher wavenumber, occurring at $v_{\max } / \mathrm{cm}^{-1} 987$ [37,38]. As Si-O bonds (1.64 $\AA$ ) are shorter than Al-O bonds (1.73 $\mathrm{A}$ ) [35], the force constant is higher for the former. Therefore, the shift to higher frequencies indicates that a loss of some aluminium from the framework has occurred.

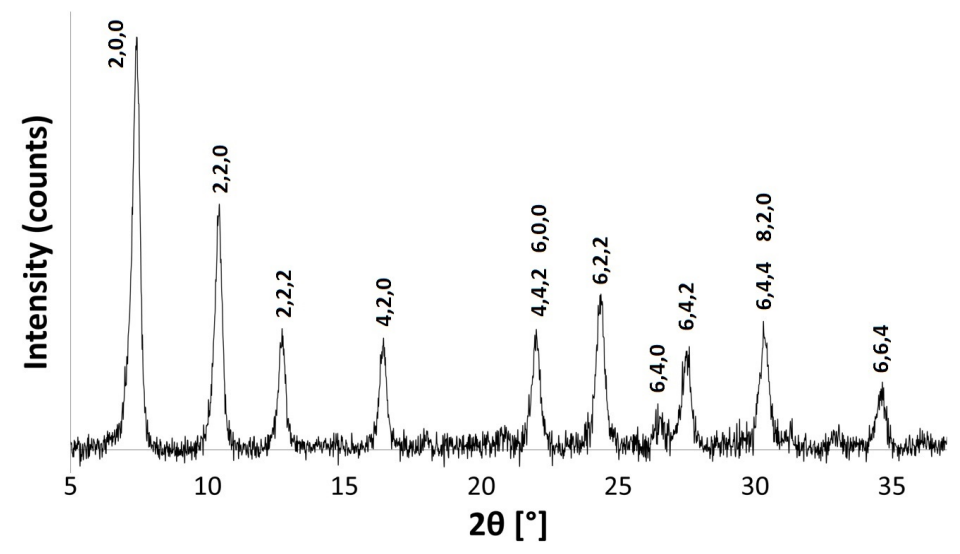

Figure 7. PXRD pattern for $\mathrm{NH}_{4}-\mathrm{A}$.

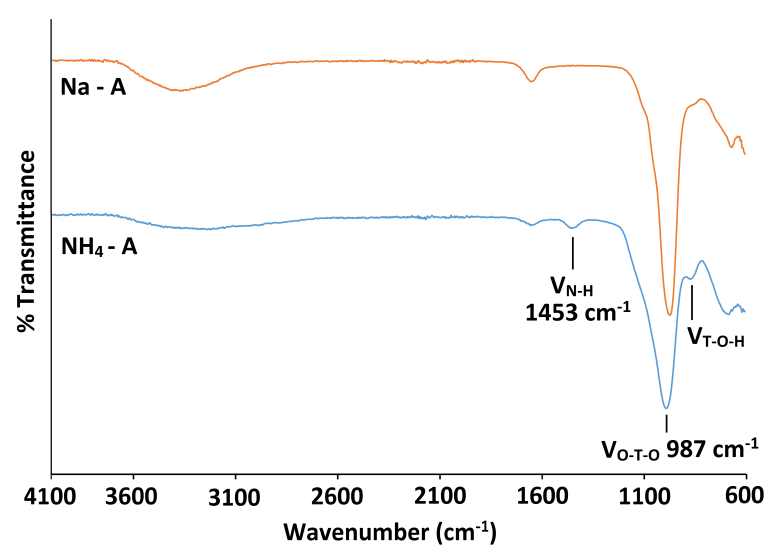

Figure 8. FT-IR spectra for the parent $\mathrm{Na}-\mathrm{A}$ zeolite (orange line) and $\mathrm{NH}_{4}$-A (blue line). 
Furthermore, deconvolution of the ${ }^{29} \mathrm{Si}$ MAS NMR, as shown in Figure 9, confirms the presence of both $\mathrm{Si}(3 \mathrm{Al})$ and $\mathrm{Si}(4 \mathrm{Al})$ environments in the framework, with peaks occurring at characteristic chemical shifts of $\delta-91.41 \mathrm{ppm}$ and $-89.08 \mathrm{ppm}$, respectively. Another peak at $\delta-85.04 \mathrm{ppm}$ is present in the spectrum due to silanol species. This is in line with the appearance of the $v_{(T-O-H)}$ stretch at $868 \mathrm{~cm}^{-1}$ in the FT-IR spectrum. Using Equation (1), the $\mathrm{Si} / \mathrm{Al}$ ratio of $\mathrm{NH}_{4}-\mathrm{A}$ was calculated to be 1.04. The loss of some aluminium from the framework is further confirmed in the ${ }^{27} \mathrm{Al}$ MAS NMR spectrum, which displays a resonance signal at $\delta 1.29 \mathrm{ppm}$, attributed to extraframework octahedrally-coordinated aluminium $[23,28]$. This peak is broad and overlaps with the main signal at $\delta 58.89 \mathrm{ppm}$ (for a tetrahedral Al coordination). The broadening and overlapping of these peaks can be attributed to severely distorted six coordinated and four coordinated aluminium environments. The presence of six coordinated extraframework $\mathrm{Al}$ species in $\mathrm{NH}_{4}$-exchanged zeolite $\mathrm{A}$ has been previously reported by Klinowski et al. [22,24], Sartbaeva et al. [15] and M. Dyballa et al. [39]. It is evident that some dealumination of the zeolite $\mathrm{A}$ framework occurs upon exchange with $\mathrm{NH}_{4}{ }^{+}$ions.
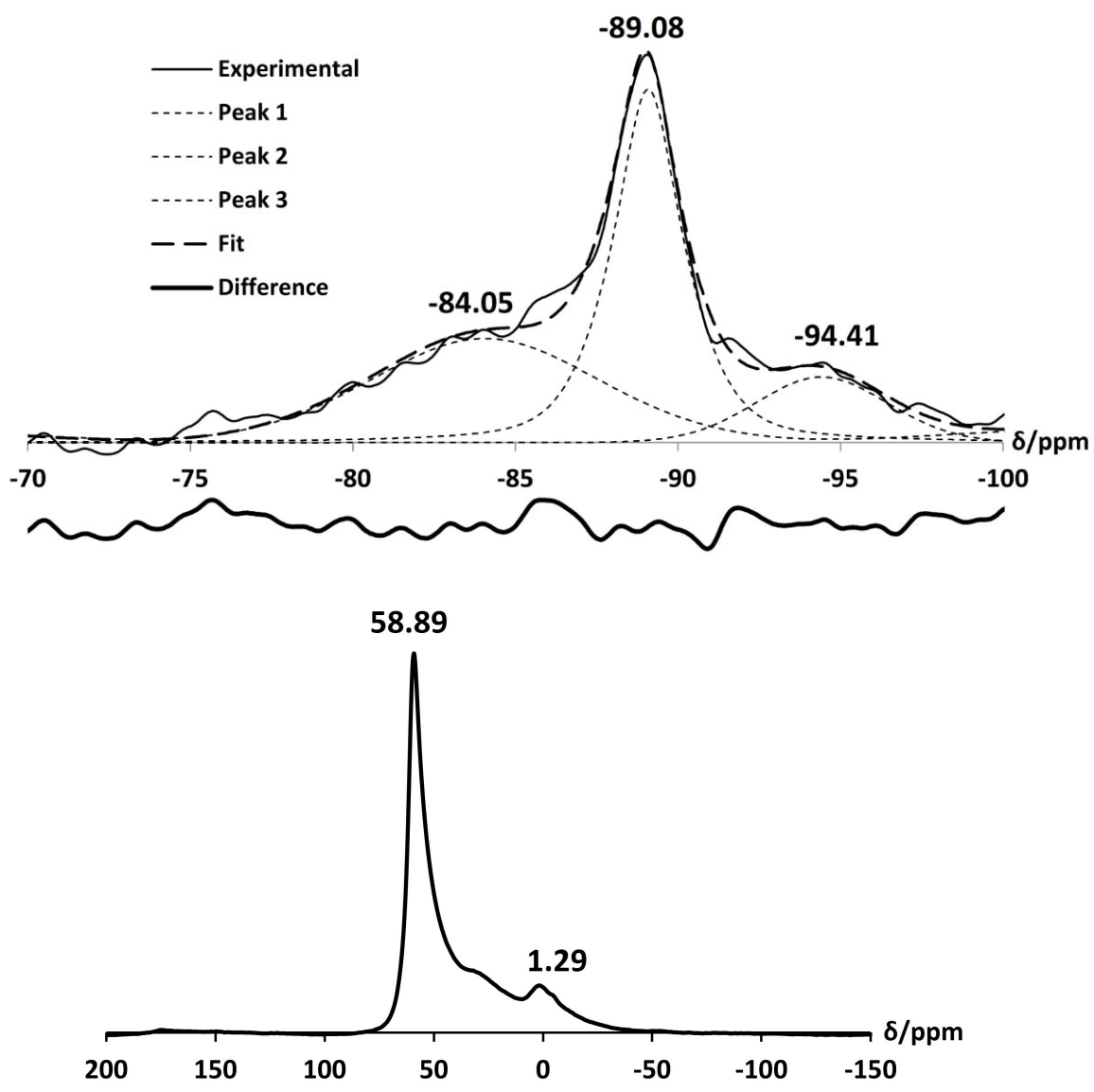

Figure 9. ${ }^{29} \mathrm{Si}$ (top) and ${ }^{27} \mathrm{Al}$ (bottom) NMR spectrum of the monovalent cation-exchanged $\mathrm{NH}_{4}$-A.

\section{3. $C a-A$}

There is no considerable alteration to the long-range crystal order of zeolite A after exchange with $\mathrm{Ca}^{2+}$. The increase in intensity of the $(4,0,0)$ reflection and the decrease of the $(4,4,0)$ reflection is consistent with the results obtained by Lührs et al. [33]. The peak in the PXRD pattern at $2 \theta 29.57^{\circ}$, as shown in Figure 10, is characteristic of calcite $\left(\mathrm{CaCO}_{3}\right)$, which must have formed from the $\mathrm{Ca}(\mathrm{OH})_{2}$ exchange solution. Further characterisation with ${ }^{13} \mathrm{C}$ Cross-Polarisation $(\mathrm{CP}) \mathrm{NMR}$ (Figure 11) shows a distinct peak centred at $\delta 168 \mathrm{ppm}$, which confirms the presence of $\mathrm{CO}_{3}{ }^{2-}$ [26]. Furthermore, the split 
bands in the FT-IR spectrum at $1413 \mathrm{~cm}^{-1}$ and $1459 \mathrm{~cm}^{-1}$ identify the carbonate as a monodentate species, as shown in Figure 12 [40].

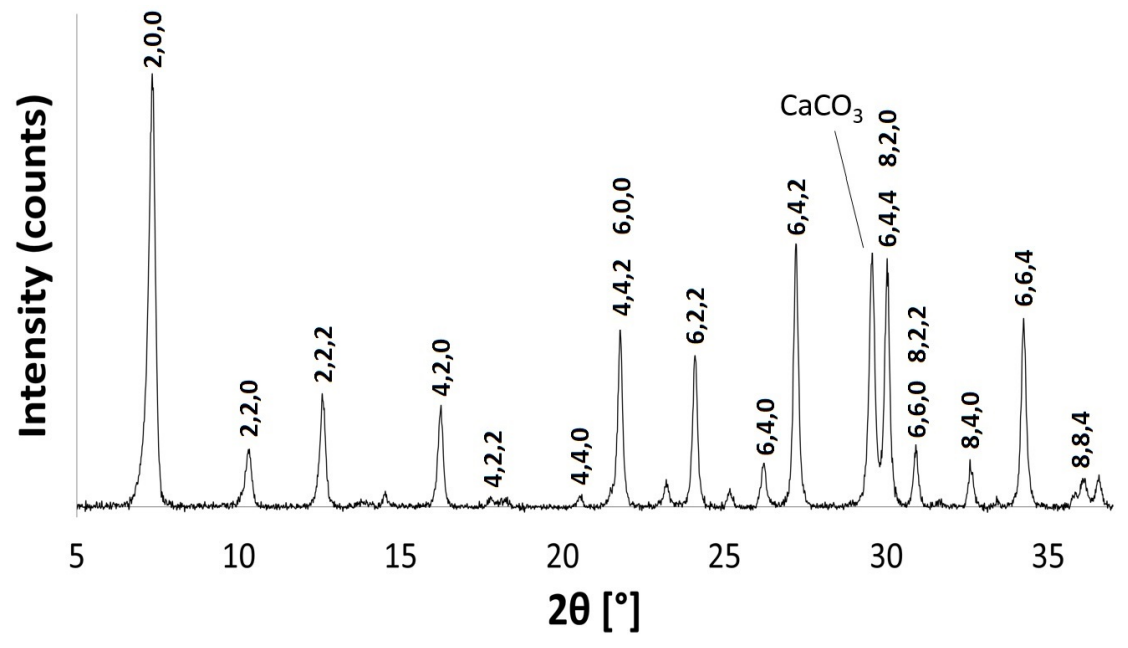

Figure 10. PXRD pattern for Ca-A. The characteristic calcite peak is identified.

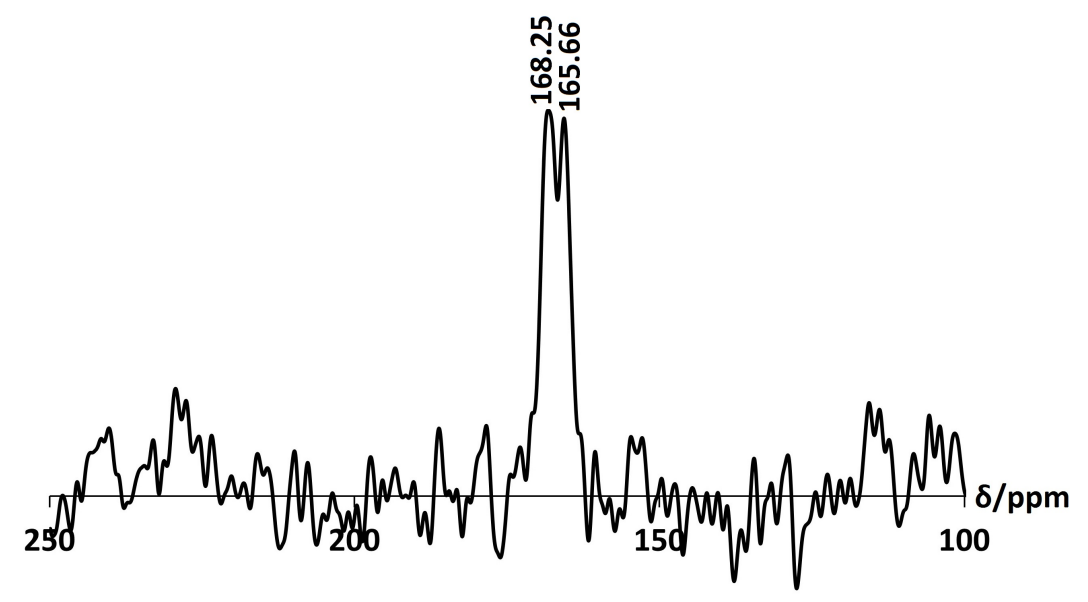

Figure 11. ${ }^{13} \mathrm{C} C \mathrm{CPNMR}$ of $\mathrm{Ca}-\mathrm{A}$.

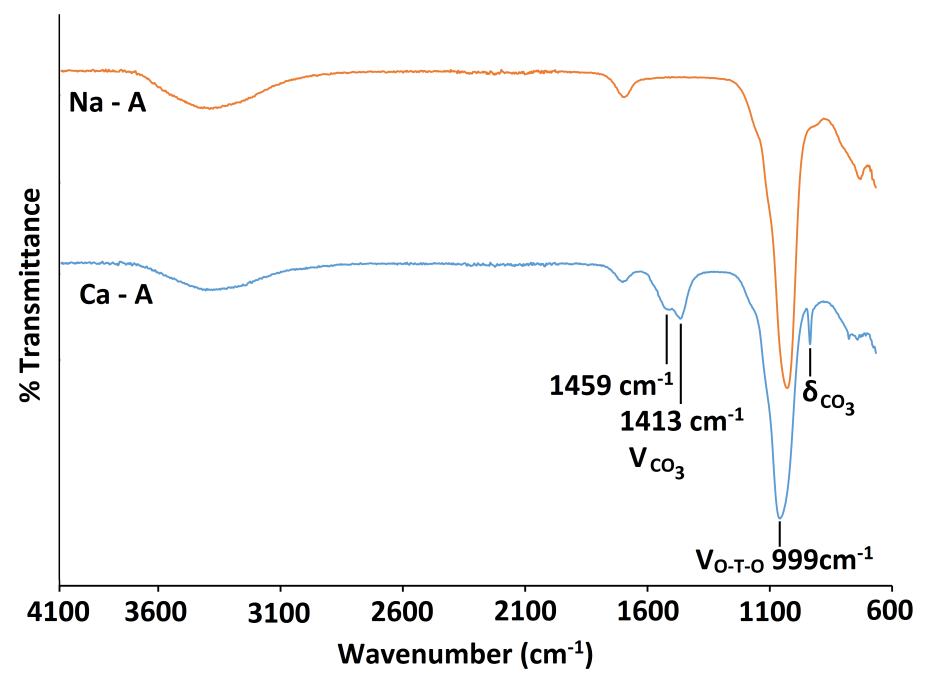

Figure 12. FT-IR spectra for the parent Na-A zeolite (orange) and Ca-A (blue). 
Exchange with $\mathrm{Ca}^{2+}$ has a small effect on the local framework environment of zeolite A. The asymmetric $v_{(O-T-O)}$ stretch in the FT-IR spectrum is less intense and is shifted toward a higher wavenumber, occurring at $v_{\max } / \mathrm{cm}^{-1} 999[37,38]$. The ${ }^{29} \mathrm{Si}$ MAS NMR spectrum, as shown in Figure 13, is dominated by an intense peak at $\delta-91.41 \mathrm{ppm}$, due to the expected $\mathrm{Si}(4 \mathrm{Al})$ units of the framework. However, deconvolution of the spectrum also confirms the presence of $\mathrm{Si}(3 \mathrm{Al})$, with a very small peak occurring at $\delta-96.35 \mathrm{ppm}$. Another peak at $\delta-85.55 \mathrm{ppm}$ is also present due to some silanol species. Using Equation (1), the $\mathrm{Si} / \mathrm{Al}$ ratio of $\mathrm{Ca}-\mathrm{A}$ was calculated to be 1.01. Similar to the exchange with $\mathrm{NH}_{4}{ }^{+}$ions, it is evident that some dealumination of the zeolite A framework has occurred upon exchange with $\mathrm{Ca}^{2+}$ ions. This loss of aluminium is confirmed in the ${ }^{27} \mathrm{Al}$ NMR spectrum, which displays a broad peak centred at $\delta 50.11 \mathrm{ppm}$, characteristic of $\mathrm{Al}(4 \mathrm{Si})$ units and also a slight peak centred at $\delta 9.10 \mathrm{ppm}$, which can be attributed to a distorted octahedral aluminium environment. The broadness of the peaks in the spectra can be attributed to quadrupolar interactions of ${ }^{27} \mathrm{Al}$ nuclei in these distorted environments.


Figure 13. ${ }^{29} \mathrm{Si}$ (top) and ${ }^{27} \mathrm{Al}$ (bottom) NMR spectrum of the divalent cation-exchanged Ca-A.

\subsection{SEM}

The surface morphologies of the zeolite crystals were observed using Field Emission Scanning Electron Microscopy (FESEM). Particle sizes were calculated from the scale bars on the FESEM micrographs, using the ImageJ processing and analysis program. The crystallite sizes were also calculated from the broadening of the most intense PXRD peaks, in this case the $(6,2,2)$ and $(6,4,4)$ reflections, using the Scherrer Equation (3), where $L$ is the crystallite size, $\beta_{(h k l)}$ is the full width at half 
maximum for the major peak of the PXRD pattern subtracting the instrumental contribution to the broadening, $K$ is the Scherrer constant, which is $0.9, \lambda$ is the wavelength of the $\mathrm{X}$-rays in nm and $\theta$ is the Bragg angle of the incident $X$-rays [41].

$$
L=\frac{K \lambda}{\beta_{(h k l)} \cos \theta}
$$

Table 3 shows the average zeolite particle sizes. For Na-A and Ca-A zeolites, there is good consistency between the sizes calculated from the Scherrer equation and FESEM data.

Figure 14 shows the FESEM micrograph for the parent Na-A zeolite. A variety of crystallite shapes and sizes can be observed, somewhere in between cubic and spherical and ranging from 122-354 nm. The visibly larger crystals with well-defined edges display the typical cubic morphology of LTA zeolites $[42,43]$. However, the low temperature conditions employed in this synthesis appear to slow down crystal growth, instead favouring nucleation in the initial stages [44]. Particles that are more rounded in shape and significantly smaller in diameter are evident in the FESEM images, indicating that some of the crystals have not had enough time to form completely. These results are in agreement with those reported by Dimitrov et al. [45] and Smaihi et al. [46]. The introduction of $\mathrm{Ca}^{2+}$ into the zeolites is accompanied by noticeable changes in the surface morphology, as shown in Figure 15.

Table 3. Crystallite sizes (nm) calculated from FESEM data using Equation (3) compared to crystal size observed by FESEM. Statistical analysis shows a large spread of values from the Scherrer equation up to $\pm 28 \mathrm{~nm}$; for FESEM data, the standard deviation is up to $\pm 14 \mathrm{~nm}$.

\begin{tabular}{ccc}
\hline & Na-A & Ca-A \\
\hline Scherrer Equation (nm) & 242 & 270 \\
FESEM (nm) & 241 & 290 \\
\hline
\end{tabular}



Figure 14. FESEM Na-A. 


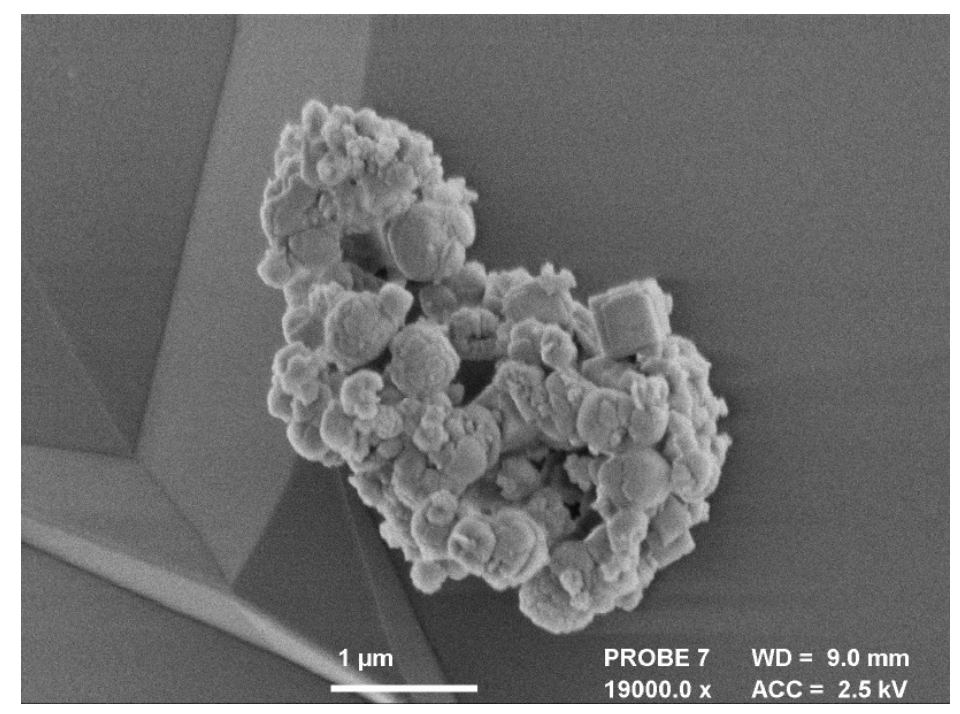

Figure 15. FESEM Ca-A.

\section{Materials and Methods}

\subsection{Synthesis of Na-A: Low Temperature and Organic Template-Free}

Zeolite A, with chemical composition $\left[\mathrm{Na}_{12}\left[\left(\mathrm{AlO}_{2}\right)_{12}\left(\mathrm{SiO}_{2}\right)_{12}\right] \cdot 27 \mathrm{H}_{2} \mathrm{O}\right.$, was prepared using a method described by Leung et al. [4]. The crystallisation process was carried out at $40^{\circ} \mathrm{C}$ in the absence of an organic template. Six-point-seven-five grams of $\mathrm{NaOH}$ pellets $(100 \% \mathrm{NaOH}$, Fischer, Ried im Innkreis, Austria) were dissolved in $40 \mathrm{~cm}^{3}$ of deionised water, and the solution was divided into two equal volumes. Zero-point-nine-eight-eight grams of $\mathrm{NaAlO}_{2}(100 \% \mathrm{Al}$, Aldrich, St. Louis, $\mathrm{MO}$, USA) were added into one bottle, and $2 \mathrm{~cm}^{3}$ of colloidal silica (Ludox HS-30, $30 \mathrm{wt} \% \mathrm{SiO}_{2}$, Aldrich, St. Louis, MO, USA) were added to the other. Both solutions were left to stir at room temperature for $90 \mathrm{~min}$ until clear. The silica solution was then poured slowly into the aluminium solution with gentle stirring. A thick gel with batch composition of $2 \mathrm{SiO}_{2}: \mathrm{Al}_{2} \mathrm{O}_{3}: 15 \mathrm{Na}_{2} \mathrm{O}: 400 \mathrm{H}_{2} \mathrm{O}$ formed, and this was shaken or stirred vigorously for $15 \mathrm{~min}$, either by hand or with a magnetic stirrer, and was put in the oven at $40{ }^{\circ} \mathrm{C}$ for $24 \mathrm{~h}$. The zeolite crystals were filtered three times with deionized water, until the $\mathrm{pH}$ of the filtrate was 7 . The product was then dried in an oven at $100{ }^{\circ} \mathrm{C}$ for a further 24 $\mathrm{h}$. In order to see the effect of temperature and time on the synthesis, the method above was varied slightly. For some samples the crystallisation temperature was increased to $50{ }^{\circ} \mathrm{C}$ for $24 \mathrm{~h}$, and for other samples, the crystallisation time was increased to $48 \mathrm{~h}$ at $40^{\circ} \mathrm{C}$.

\subsection{Ion Exchange}

The cation sources used for ion exchange were $\mathrm{LiOH}, \mathrm{KCl}, \mathrm{RbOH}, \mathrm{Ca}(\mathrm{OH})_{2}$ and $\mathrm{NH}_{4} \mathrm{Br}$. The mass of each cation source was calculated so that the exchange solutions contained a surplus of the exchanging cation that was twice the theoretical amount of $\mathrm{Na}^{+}$in the pores of $1 \mathrm{~g}$ of Na-A. The appropriate cation source was dissolved in $50 \mathrm{~cm}^{3}$ of deionized water. One gram of the parent $\mathrm{Na}-\mathrm{A}$ zeolite was added, and the solution was stirred for $6 \mathrm{~h}$ at $65^{\circ} \mathrm{C}$. This was then filtered and washed with deionized water and the exchanged zeolite left in an oven to dry overnight at $100{ }^{\circ} \mathrm{C}$. The filtrates were kept in order to quantify the amounts of exchange that had taken place using the sodium ion selective electrode. 


\subsection{Product Characterisation}

\subsubsection{Powder X-ray Diffraction}

PXRD patterns were recorded at room temperature using a BRUKER AXS D8 Advance diffractometer equipped with a Vantec- 1 detector using $\mathrm{Cu}-\mathrm{K} \alpha$ radiation $(\lambda=1.54)$ in flat plate mode. The scan range was from $3^{\circ}<2 \theta<60^{\circ}$ over $20 \mathrm{~min}$. The unit cell parameters for the samples were calculated using the program UnitCell [34].

\subsubsection{Solid State Nuclear Magnetic Resonance}

${ }^{29} \mathrm{Si},{ }^{27} \mathrm{Al},{ }^{23} \mathrm{Na}$ and ${ }^{13} \mathrm{C}$ NMR spectra were measured by a VARIAN VNMRS 400 spectrometer using the Direct Excitation (DE) method, with neat tetramethylsilane (TMS), $1 \mathrm{M}$ aqueous $\mathrm{Al}\left(\mathrm{NO}_{3}\right)_{3}$ and $1 \mathrm{M}$ aqueous $\mathrm{NaCl}$ as references. ${ }^{13} \mathrm{C}$ Cross-Polarisation (CP) MAS-NMR was used for Ca-A to enhance the signal. The spinning rates of ${ }^{29} \mathrm{Si}$ and ${ }^{13} \mathrm{C}$ NMR were $6.0 \mathrm{kHz}$ and for ${ }^{27} \mathrm{Al}$ and ${ }^{23} \mathrm{Na} \mathrm{NMR}$ were $12 \mathrm{kHz}$. The frequency of ${ }^{29} \mathrm{Si}$ NMR was $79.438 \mathrm{MHz}$ and for ${ }^{27} \mathrm{Al} 104.199 \mathrm{MHz}$. The spectral width of ${ }^{29} \mathrm{Si} \mathrm{NMR}$ was $40,322.6 \mathrm{~Hz}$ and for ${ }^{27} \mathrm{Al} 416.7 \mathrm{~Hz}$. Solid-state NMR spectra were obtained at the EPSRC U.K. National Solid-state NMR Service at Durham.

\subsubsection{Scanning Electron Microscopy and Energy Dispersive X-ray Spectroscopy}

Low resolution micrographs were taken using a JEOL SEM6480LV scanning electron microscope. EDX data were acquired using an Oxford INCA X-ray analyser attached to the microscope with an acceleration voltage of $20 \mathrm{kV}$.

High resolution micrographs were taken using a JEOL FESEM6301F field emission scanning electron microscope (FESEM). The powder samples for FESEM were coated with $5 \mathrm{~nm}$ chromium to prevent surface charging after EDX data were collected.

\subsubsection{Fourier Transform Infrared Spectroscopy}

FT-IR spectra for the powder samples were recorded using a Perkin Elmer 100 FT-IR Spectrometer in the range of $4000-600 \mathrm{~cm}^{-1}$.

\subsubsection{Sodium Ion Selective Electrode}

The concentration of $\mathrm{Na}^{+}$in the exchange filtrates was calculated using a Cole-Parmer double junction, combination sodium Ion Selective Electrode (ISE) filled with a reference solution of $0.1 \mathrm{M} \mathrm{NH}_{4} \mathrm{Cl}$ and connected to a $\mathrm{pH} / \mathrm{mV}$ meter.

\section{Conclusions}

Solid state NMR revealed changes to the local structure of the LTA framework upon ion exchange with $\mathrm{NH}_{4}{ }^{+}$and $\mathrm{Ca}^{2+}$. Exchange with $\mathrm{Li}^{+}, \mathrm{K}^{+}$and $\mathrm{Rb}^{+}$ions does not significantly affect the long-range crystal order. Exchange with $\mathrm{NH}_{4}{ }^{+}$ions compromises some of the long-range order of the zeolite $\mathrm{A}$ crystals due to the loss of some framework aluminium as can be seen from X-ray data. Exchange with divalent $\mathrm{Ca}^{2+}$ ions introduces some monodentate carbonate species into the framework, but no alteration to the long-range crystal order is observed. This study confirms that using a local probe such as SS NMR alongside PXRD and other long-range methods to study zeolites can reveal an extra level of information about the structure of those useful minerals, which will further their use as potential catalysts and ion exchange materials.

Acknowledgments: A.S. would like to acknowledge the Royal Society for funding of URF. We thank John Mitchel and Ursula Potter for help with collecting SEM data and Fraser Markwell for collecting SS NMR data at the EPSRC-funded SS NMR facility at Durham University.

Author Contributions: A.S. conceived the study. K.M.L. designed experiments. L.P. and K.M.L. have collected data and performed data analysis. All authors contributed to writing and editing the manuscript. 
Conflicts of Interest: The authors declare no conflict of interest.

\section{References}

1. Baerlocher, C.; McCusker, L.B.; Olson, D.H. Atlas of Zeolite Framework Types; Elsevier: Amsterdam, The Netherlands, 2017.

2. Sartbaeva, A.; Wells, S.A.; Treacy, M.M.J.; Thorpe, M.F. The flexibility window in zeolites. Nat. Mat. 2006, 5, 962-965, doi:10.1038/nmat1784.

3. Conato, M.T.; Oleksiak, M.D.; McGrail, B.P.; Motkuri, R.K.; Rimer, J.D. Framework Stabilization of Si-Rich LTA Zeolite Prepared in Organic-Free Media. Chem. Commun. 2014, 51, 269-272, doi:10.1039/C4CC07396G.

4. Leung, K.M.; Edwards, P.P.; Jones, E.; Sartbaeva, A. Microwave synthesis of LTN framework zeolite with no organic structure directing agents. RSC Adv. 2015, 5, 35580-35585, doi:10.1039/C4RA16583G.

5. Nearchou, A.; Raithby, P.; Sartbaeva, A. Systematic approaches towards template-free synthesis of EMT-type zeolites. Microporous Mesoporous Mater. 2018, 255, 261-270, doi:10.1016/j.micromeso.2017.08.036.

6. Nearchou, A.; Sartbaeva, A. Influence of alkali metal cations on the formation of zeolites under hydrothermal conditions with no organic structure directing agents. CrystEngComm 2008, 17, 2496-2503, doi:10.1039/C4CE02119C.

7. Maldonado, M.; Oleksiak, M.D.; Chinta, S.; Rimer, J.D. Controlling Crystal Polymorphism in Organic-Free Synthesis of Na-Zeolites. J. Am. Chem. Soc. 2012, 135, 2641-2652, doi:10.1021/ja3105939.

8. Nicholas, C.P. Zeolites in Industrial Separation and Catalysis; Wiley VCH: Weinheim, Germany, 2010; pp. 355-402.

9. Amorim, R.; Vilaça, N.; Martinho, O.; Reis, R.M.; Sardo, M.; Rocha, J.; Fonseca, A.M.; Baltazar, F.; Neves, I.C. Zeolite Structures Loading with an Anticancer Compound As Drug Delivery Systems. J. Phys. Chem. C 2012, 116, 25642-25650, doi:10.1021/jp3093868.

10. Chaves, T.F.; Soares, F.; Cardoso, D.; Carneiro, R.L. Monitoring of the crystallization of Zeolite LTA using Raman and Chemometric tools. Analyst 2015, 140, 854-859, doi:10.1039/C4AN00913D.

11. Lalik, E.; Mirek, R.; Rakoczy, J.; Groszek, A. Microcalorimetric study of sorption of water and ethanol in zeolites 3A and 5A. Catal. Today 2006, 114, 242-247.

12. Liu, Q.; Mace, A.; Bacsik, Z.; Sun, J.; Laaksonen, A.; Hedin, N. NaKA sorbents with high $\mathrm{CO}_{2}$-over- $\mathrm{N}_{2}$ selectivity and high capacity to adsorb $\mathrm{CO}_{2}$. Chem. Comm. 2010, 46, 4502-4504, doi:10.1039/C000900H.

13. Sun, H.; Wu, D.; Guo, X.; Shen, B.; Liu, J.; Navrotsky, A. Energetics of Confinement of n-Hexane in Ca-Na Ion Exchanged Zeolite A. J. Phys. Chem. C 2014, 118, 25590-25596, doi:10.1021/jp508514e.

14. Kwakye-Awuah, B.; Labik, L.K.; Nkrumah, I.; Williams, C. Removal of ammonium ions by laboratory synthesized zeolite linde type A adsorption from water samples affected by mining activities in Ghana. J. Water Health 2014, 12, 151-160, doi:10.2166/wh.2013.093.

15. Sartbaeva, A.; Rees, N.H.; Edwards, P.P.; Ramirez-Cuesta, A.J.; Barney, E. Local probes show that framework modification in zeolites occurs on ammonium exchange without calcination. J. Mater. Chem. A 2013, 1, 7415-7421, doi:10.1039/C3TA10243B.

16. Seel, A.G.; Sartbaeva, A.; Edwards, P.P.; Rammirez-Cuesta, A.J. Inelastic neutron scattering of Na-zeolite A with in situ ammoniation: An examination of initial coordination. Phys. Chem. Chem. Phys. 2010, 12, 9661-9666.

17. Watanabe, Y.; Yamada, H.; Tanaka, J.; Komatsu, Y.; Moriyoshi, Y. Ammonium Ion Exchange of Synthetic Zeolites: The Effect of Their Open Window Sizes, Pore Structures, and Cation Exchange Capacities. Sep. Sci. Technol. 2005, 39, 2091-2104, doi:10.1081/SS-120039306.

18. Navarrete-Casas, R.; Navarrete-Guijosa, A.; Valenzuela-Calahorro, C.; López-González, J.D.; García-Rodríguez, A. Study of lithium ion exchange by two synthetic zeolites: Kinetics and equilibrium. J. Colloid Interface Sci. 2007, 306, 345-353, doi:10.1016/j.jcis.2006.10.002.

19. Kim, H.S.; Choi, S.Y.; Lim W.T. Complete $\mathrm{Li}^{+}$exchange into zeolite $\mathrm{X}(\mathrm{FAU}, \mathrm{Si} \backslash \mathrm{Al}=1.09)$ from undried methanol solution. J. Porous Mater. 2013, 20, 1449-1456, doi:10.1007/s10934-013-9731-1.

20. Bignami, G.P.; Dawson, D.M.; Seymour, V.R.; Wheatley, P.S.; Morris, R.E.; Ashbrook, S.E. Synthesis, Isotopic Enrichment, and Solid-State NMR Characterization of Zeolites Derived from the Assembly, Disassembly, Organization, Reassembly Process. J. Am. Chem. Soc. 2017, 139, 5140-5148. 
21. Brouwer, D.H.; Darton, R.J.; Morris, R.E.; Levitt, M.H. A solid-state NMR method for solution of zeolite crystal structures. J. Am. Chem. Soc. 2005, 127, 10365-10370, doi:10.1021/ja052306h.

22. Fyfe, C.A.; Feng, Y.; Grondey, H.; Kokotailo, G.T.; Gies, H. One- and two-dimensional high-resolution solid-state NMR studies of zeolite lattice structures. Chem. Rev. 1991, 91, 1525-1543, doi:10.1021/cr00007a013.

23. Fyfe, C.A.; Gobbi, G.C.; Hartman, J.S.; Klinowski, J.; Thomas, J.M. Solid-state magic-angle spinning. Aluminum-27 nuclear magnetic resonance studies of zeolites using a 400-MHz high-resolution spectrometer. J. Phys. Chem. 1982, 86, 1247-1250, doi:10.1021/j100397a006.

24. Fyfe, C.A.; Thomas, J.M.; Klinowski, J.; Gobbi, G.C. Magic-Angle-Spinning NMR (MAS-NMR) Spectroscopy and the Structure of Zeolites. Angew. Chem. Int. Ed. Engl. 1983, 22, 259-275, doi:10.1002/anie.198302593.

25. Lippmaa, A.; Maedi, M.; Samoson, A.; Tarmak, M.; Engelhardt, G. Investigation of the structure of zeolites by solid-state high-resolution silicon-29 NMR spectroscopy. J. Am. Chem. Soc. 1981, 103, 4992-4996, doi:10.1021/ja00407a002.

26. Nebel, H.; Neumann, M.; Mayer, C.; Epple, M. On the Structure of Amorphous Calcium Carbonate-A Detailed Study by Solid-State NMR Spectroscopy. Inorg. Chem. 2008, 47, 7874-7879, doi:10.1021/ic8007409.

27. Park, M.B.; Vicente, A.; Fernandez, C.; Hong, S.H. Solid-state NMR study of various mono- and divalent cation forms of the natural zeolite natrolite. Phys. Chem. Chem. Phys. 2013, 15, 7604-7612; doi:10.1039/C3CP44421J.

28. Thomas, J.M.; Klinowsky, J.; Ramadas, S.; Anderson, M.W.; Fyfe, C.A.; Gobbi, G.C. New Approaches to the Structural Characterization of Zeolites: Magic-Angle Spinning NMR (MASNMR). In Intrazeolite Chemistry; Galen, D.S., Francis, G.D., Eds.; ACS Publications: Washington, DC, USA, 1983; pp. 159-180, ISBN 9780841207745.

29. Gramlich, V.; Meier, W.M. The crystal structure of hydrated NaA: A detailed refinement of a pseudosymmetric zeolite structure. Z. Krist. 1971, 10, 134-149, doi:10.1524/zkri.1971.133.133.134.

30. Treacy, M.M.J.; Higgins, J.B. Collection of Simulated XRD Powder Patterns for Zeolites; Elsevier: Amsterdam, The Netherlands, 2007; pp. 252-253.

31. Alfaro, S.; Rodriguez, C.; Valenzuela, M.A.; Bosch, P. Aging time effect on the synthesis of small crystal LTA zeolites in the absence of organic template. Mater. Lett. 2007, 61, 4655-4658, doi:10.1016/j.matlet.2007.03.009.

32. Carey, T.; Tang, C.C.; Hriljac, J.A.; Anderson, P.A. Chemical Control of Thermal Expansion in Cation-Exchanged Zeolite A. Chem. Mater. 2014, 26, 1561-1566, doi:10.1021/cm403312q.

33. Lührs, H.; Derr, J.; Fischer, R.X. K and Ca exchange behavior of zeolite A. Microporous Mesoporous Mater. 2012, 151, 457-465, doi:10.1016/j.micromeso.2011.09.025.

34. Holland, T.J.B.; Redfern, S.A.T. Unit cell refinement from powder diffraction data-the use of regression diagnostics. Miner. Mag. 1997, 61, 65-77.

35. O'Keeffe, M.; Navrotsky, A.; Some Aspects of the Ionic Model of Crystals. In Structure and Bonding in Crystals; O’Keeffe, M., Ed.; Academic Press: Cambridge, MA, USA, 1981; pp. $299-322$.

36. Ramdas, S.; Klinowski, J. A simple correlation between isotropic 29Si-NMR chemical shifts and T-O-T angles in zeolite frameworks. Nature 1984, 308, 521-523, doi:10.1038/308521a0.

37. Edith, M.F.; Hassan, K.; Herman, A.S. Infrared Structural Studies of Zeolite Frameworks. In Molecular Sieve Zeolites-I; Edith M.F., Leonard B.S., Eds.; ACS Publications: Washington, DC, USA, 1974; pp. 201-229, ISBN 9780841201149.

38. Milkey, R.G. Infrared Spectra of some Tectosilicates. Am. Minerol. 1960, 45, 990-1007.

39. Dyballa, M.; Obenaus, U.; Lang, S.; Gehring, B.; Traa, Y.; Koller, H.; Hunger, M. Brønsted sites and structural stabilization effect of acidic low-silica zeolite A prepared by partial ammonium exchange. Microporous Mesoporous Mater. 2015, 212, 110-116, doi:10.1016/j.micromeso.2015.03.030.

40. Ucun, F. An Infrared Study of the CaA Zeolite Reacted with $\mathrm{CO}_{2}$. Z. Naturforsch. 2002, 57, 283.

41. Holzwarth, U.; Gibson, N. The Scherrer equation versus the 'Debye-Scherrer equation'. Nat. Nano 2011, 6, 534.

42. Cubillas, P.; Gebbie, J.T.; Stevens, S.M.; Blake, N.; Umemura, A.; Terasaki, O.; Anderson, M.W. Atomic Force Microscopy and High Resolution Scanning Electron Microscopy Investigation of Zeolite A Crystal Growth. Part 2: In Presence of Organic Additives. J. Phys. Chem. C 2014, 118, 23092-23099, doi:10.1021/jp506222y.

43. Kliewer, C.E. Electron Microscopy and Imaging. In Zeolite Characterization and Catalysis; Chester, A.W., Derouane, E.G., Eds.; Springer: Dordrecht, The Netherlands, 2009; pp. 169-196.

44. Mintova, S.; Olson, N.H.; Valtchev, V.; Bein, T. Mechanism of Zeolite A Nanocrystal Growth from Colloids at Room Temperature. Science 1999, 283, 958-960, doi:10.1126/science.283.5404.958. 
45. Dimitrov, L.; Valtchev, V.; Nihtianova, D.; Kalvachev, Y. Submicrometer Zeolite A Crystals Formation: Low-Temperature Crystallization Versus Vapor Phase Gel Transformation. Cryst. Growth Des. 2011, 11, 4958-4962, doi:10.1021/cg2008667.

46. Smaihi, M.; Barida, O.; Valtchev, V. Investigation of the Crystallization Stages of LTA-Type Zeolite by Complementary Characterization Techniques. Eur. J. Inorg. Chem. 2003, 2003, 4370-4377, doi:10.1002/ ejic.200300154.

(C) 2017 by the authors. Licensee MDPI, Basel, Switzerland. This article is an open access article distributed under the terms and conditions of the Creative Commons Attribution (CC BY) license (http:/ / creativecommons.org/licenses/by/4.0/). 